\title{
Ultrasonic Surface Hardening of Low Carbon Steels and Non-Ferrous Alloys
}

\author{
Kharis Rakhimyanov ${ }^{1}$, Viktor Gileta ${ }^{1}$ and Artem Samul ${ }^{1, *}$ \\ ${ }^{1}$ Novosibirsk State Technical University, 630073, Prospekt K. Marks, 20, Novosibirsk, Russia
}

\begin{abstract}
The possibility of using ultrasonic surface hardening with implementing the indenter tangential oscillations to the deformed surface to improve the quality of the detail surface layer produced from low carbon steel and ferrous alloys is considered in the paper. The mathematical description of the trajectory of the relative displacement of the instrument and the detail is presented. It is established that the important technological parameter influencing the character of the formed micro-geometry is the angle between the instrument vectors and the detail speed. The effect of the technological factors of the ultrasonic surface hardening on the amplitude and spacing parameters of the surface roughness are revealed. The results of the research showed that the ultrasonic processing at the tangential oscillations of the indenter allows forming a stable micro-geometrical state of the surface layer with low values of the amplitude and spacing parameters on the details made from non-ferrous alloys and low carbon steels.
\end{abstract}

\section{Introduction}

The ever-increasing requirements to the quality of machines and devices manufactured are connected with the necessity of increasing their accuracy and reliability, production efficiency and the efficiency factor, which determine their service properties. Numerous investigations showed that in up to $80 \%$ cases the breakdown of the machines during the operation takes place because of the wearing in conjugated parts of friction [1].

Service properties of the device details depend on the surface layer of the contacted surfaces, which is characterized by geometrical (macro-deviation, waviness and roughness), physical and mechanical (micro-hardness, residual tenses and structure) characteristics as well as the relative location of micro-roughness of the conjugated surfaces [2].

To increase the quality of the surface layer, the methods of the surface hardening are used. One of such methods is the ultrasonic hardening, which is characterized by specific parameters of processing. The ultrasonic hardening with implementing oscillations perpendicular to the surface is well studied and is widely used for processing the details made of metals and alloys with high hardness [3 - 13]. Processing the details of materials with low hardness according to the scheme mentioned has its own limitations due to a considerable material viscosity in the deforming zone, which leads to appearing the waviness on the processed surface [14 - 15]. So, to form the surface layer of high quality of details made of low carbon steels and non-ferrous alloys, the possibility of using the ultrasonic processing with implementing the tangential oscillations to the processed surface was studied.

* Corresponding author. Tel.:+7-913-451-88-28.

E-mail address: artem-samul@mail.ru 
Taking into account the above said, the goal of the paper under consideration is to determine the possibilities of using the ultrasonic surface hardening at tangential oscillations to form a stable quality of the surface layer with low amplitude and spacing characteristics of micro-geometry.

\section{Description of the Scheme of Ultrasonic Strengthening and Finishing Processing in Tangential Oscillations}

To improve the quality of the surface layer of details made of low carbon steels and nonferrous alloys, it is suggested to use the ultrasonic surface hardening with the indenter tangential motion to the processed surface (Figure 1). The application of such a scheme has its own peculiarities and is characterized by the consistency of the indenter contact with the processed detail.

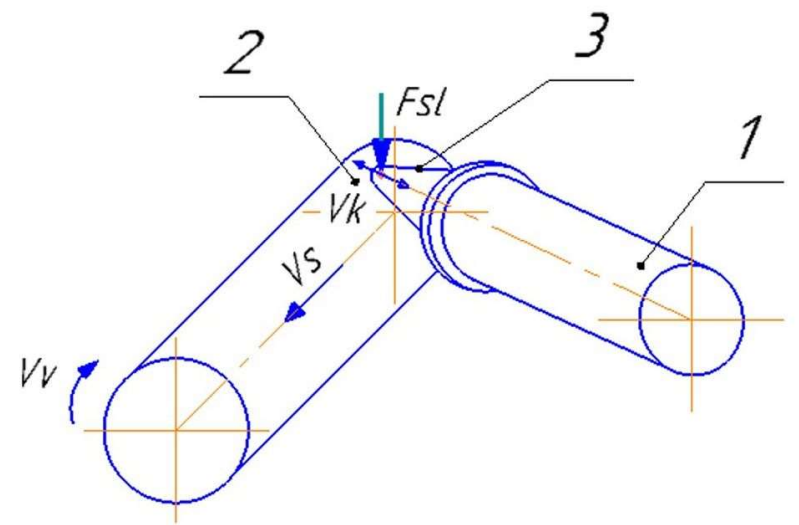

Fig. 1. Scheme of the ultrasonic surface hardening at the tangential oscillations of the indenter: 1 - magnetostriction converter; 2 - the processed detail; 3 - the ultrasonic tool of longitudinal oscillations, $V_{k}$ - the oscillating speed, $V_{v}$ - the rotation velocity of the detail, $V_{s}$ - the feed velocity, $P_{s l}$ - the static load

The character of the relative position of velocities mentioned above during the ultrasonic surface hardening is presented in Figure 2. 


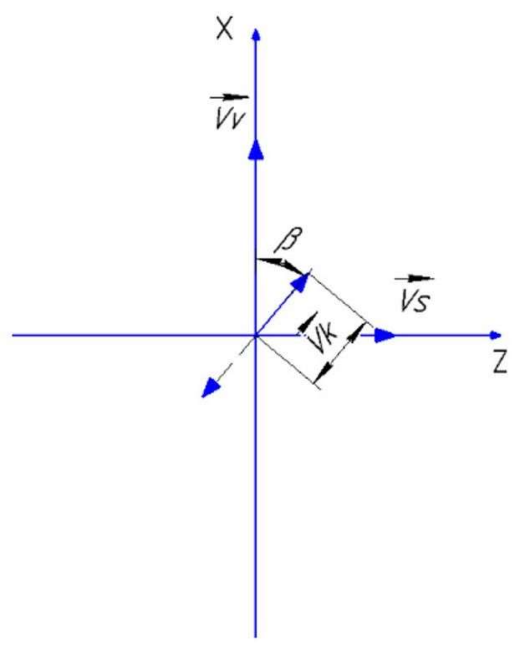

Fig. 2. Direction of the velocity vectors in the Cartesian reference system: $\overrightarrow{V_{S}}$ - the vector of the instrument feed velocity; $\overrightarrow{V_{V}}-$ the vector of the detail rotational velocity; $\overrightarrow{V_{K}}$ - the vector of the instrument oscillating speed; $\beta$ - the angle between the directions of the detail velocity and the instrument oscillating speed

The geometrical as well as physical and mechanical state of the surface layer considerably depends on the character of the relative displacement of the instrument and the detail during the processing. So, to determine the character of the micro-geometry formed, it is necessary to know the consistent pattern of this motion and the effect of the processing parameters on them. The instrument displacement in the Cartesian reference system ZXt is described by the equations:

$$
\left\{\begin{array}{l}
Z=V_{S} t+A_{0} \sin (2 \pi f t) \\
X=V_{V} t+A_{0} \sin (2 \pi f t)
\end{array}\right.
$$

where $A_{0}$ - the oscillation amplitude $(\mu \mathrm{m}) ; f-$ the oscillation frequency $\left(\mathrm{sec}^{-1}\right) ; t-$ time (sec).

The solution to the equations (1) and (2) allows establishing the trajectory of the instrument displacement relative to the processed surface, which is presented in Figure 3. 


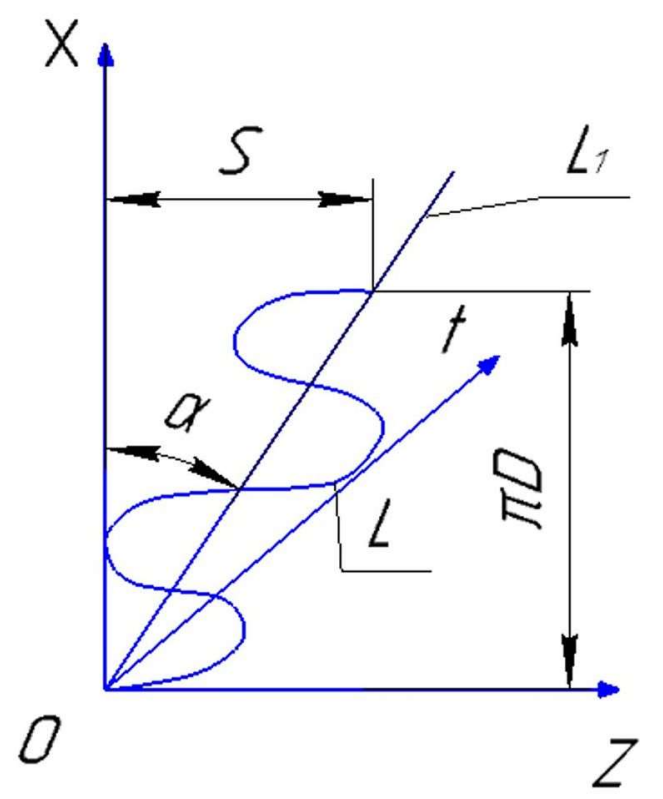

Fig. 3. Trajectory of the indenter displacement at ultrasonic oscillations: $L$ - the trajectory of the imprint; $L_{l}$ - the center line of the imprint; $\alpha$ - the inclination angle of the trace trajectory; $S$ - the feed; $D$ - the specimen diameter

In addition to the technological parameters inherent to the scheme with implementing oscillations perpendicular to the processed surface, there is an additional parameter in this scheme. It is the angle $\beta$ between the vectors of the instrument oscillatory velocity and the detail speed, which also affects physical and mechanical as well as microgeometrical parameters of the surface layer.

In the presence of the angle $\beta$ the indenter trajectory displacement is described by the equations:

$$
\left\{\begin{array}{l}
Z=V_{S} t+A_{0} \sin (2 \pi f t) \sin \beta \\
X=V_{V} t+A_{0} \sin (2 \pi f t) \cos \beta
\end{array}\right.
$$

Trajectory of the instrument motion $(\mathrm{Y})$ is described by the equation:

$$
Y=\sqrt{X^{2}+Z^{2}}
$$

The presence of angle $\beta$ changes the trajectory of the instrument displacement, particularly influences the width of the trace sinusoidal waves. The shape of the imprint at different values of angle $\beta$ is presented in Figures $4-5$. 


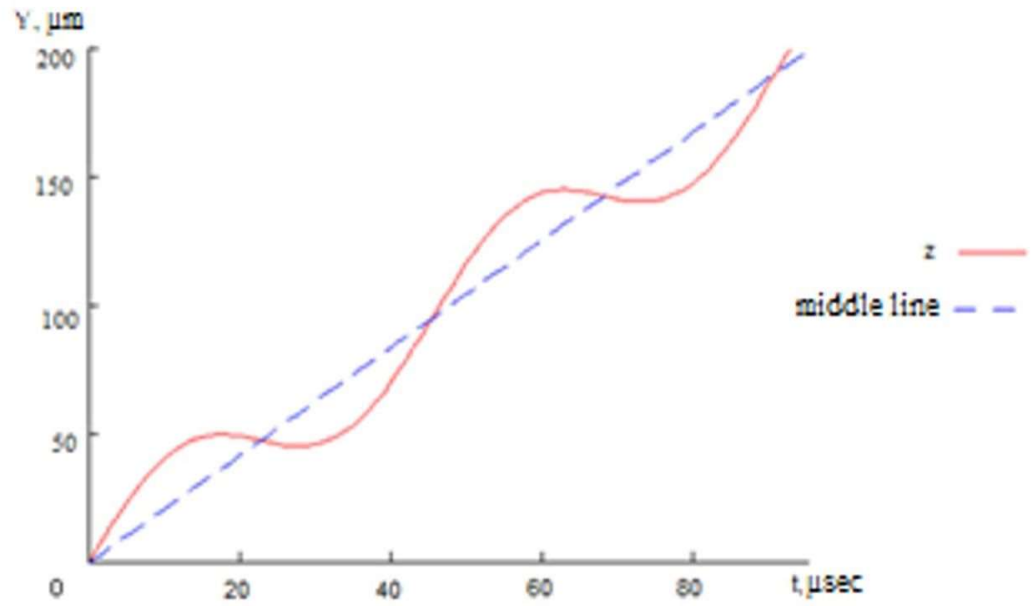

Fig. 4. Trajectory of the indenter motion at $\beta=\pi / 2$

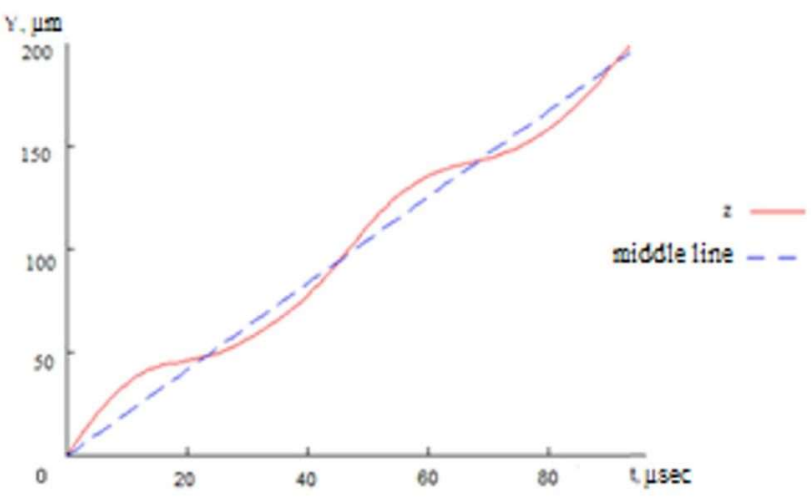

Fig. 5. Trajectory of the indenter motion at $\beta=\pi / 6$

\section{Materials, Equipment and Investigation Methods}

The ultrasonic surface hardening was conducted on the specimens made of aluminum alloy AlCuMg2 (105 HB), copper SF-Cu (75 HB) and steel Fe360B (131 HB). The specimen diameters are equal to $49 \mathrm{~mm}, 59 \mathrm{~mm}$ and $40 \mathrm{~mm}$, respectively. The specimens were preliminary processed at the lathe at the following modes: $V=70 \mathrm{~m} / \mathrm{min}, S=0.07$ $\mathrm{mm} / \mathrm{rev}, t=0.5 \mathrm{~mm}$. The ultrasonic surface hardening was done by using the ultrasonic generator IL10-1.0 and the magnetostriction converter with a frequency of $18 \mathrm{kHz}$. Synthetic diamonds of polycrystalline synthetic diamonds (PSD) type with a radius of $4 \mathrm{~mm}$ served as an instrument working section (indenters). The processing parameters for specimens of aluminum alloy $\mathrm{AlCuMg} 2$ were the following: constant $-S=0.07 \mathrm{~mm} / \mathrm{rev}, V=89 \mathrm{~m} / \mathrm{min}$, $2 A=40 \mu \mathrm{m}$; variable $-P_{s l}=30 \ldots 60 \mathrm{H}, \beta=30 \ldots 45^{\circ}$. Copper SF-Cu specimens were processed at the following modes: constant $-P_{s l}=60 \mathrm{H}, S=0.07 \mathrm{~mm} / \mathrm{rev}, V=56 \mathrm{~m} / \mathrm{min}$, $2 A=40 \mu \mathrm{m}$; variable $-\beta=0 \ldots 60^{\circ}$. The constant parameters of processing steel $\mathrm{Fe} 360 \mathrm{~B}$ during the ultrasonic surface hardening were $S=0.07 \mathrm{~mm} / \mathrm{rev}, V=32 \mathrm{~m} / \mathrm{min}, 2 A=40 \mu \mathrm{m}$; and variable characteristics $-P_{s l}=40 \ldots 110 \mathrm{H}, \beta=0 \ldots 45^{\circ}$. The diamond smoothening (DS) 
of steel Fe360B specimens was done at the following modes $-S=0.07 \mathrm{~mm} / \mathrm{rev}, V=32$ $\mathrm{m} / \mathrm{min}, P_{s l}=40 \ldots 70 \mathrm{H}$.

The surface topography and micro-geometrical parameters of the surface layer were studied by the instrumental microscope Nikon MM- 400 and the profilograph-profilometer of 252 model.

\section{Results and Discussion}

The investigation results of the specimens of aluminum alloy AlCuMg2 (105 HB) copper SF-Cu ( $75 \mathrm{HB})$ and steel Fe360B (131 HB) after the ultrasonic surface hardening at tangential oscillations with a varied static load $\left(P_{s l}, \mathrm{H}\right)$ and the angle of oscillation direction $\left(\beta,{ }^{\circ}\right)$ are presented in Tables 1 and 2.

Table 1. Change in the roughness of the aluminum alloy $\mathrm{AlCuMg} 2$ and copper $\mathrm{SF}-\mathrm{Cu}$ processed specimens depending on the processing conditions

\begin{tabular}{|l|c|c|c|c|c|c|c|c|c|}
\hline Specimen, № & $\begin{array}{c}\mathbf{0 1} \\
(\mathbf{i n i})\end{array}$ & $\mathbf{0 2}$ & $\mathbf{0 3}$ & $\mathbf{0 4}$ & $\mathbf{0 5}$ & $\mathbf{0 6}$ & $\begin{array}{c}\mathbf{1 0} \\
\text { (ini) }\end{array}$ & $\mathbf{1 1}$ & $\mathbf{1 2}$ \\
\hline $\begin{array}{l}\text { Static load } \\
\left(P_{s l}, \mathrm{H}\right)\end{array}$ & - & 30 & 40 & 60 & 40 & 50 & - & 60 & 60 \\
\hline $\begin{array}{l}\text { Angle of oscillation } \\
\text { direction }\left(\beta,{ }^{\circ}\right)\end{array}$ & - & 45 & 45 & 45 & 30 & 30 & - & 0 & 60 \\
\hline $\begin{array}{l}\text { Roughness } \\
\left(R_{a}, \mu \mathrm{m}\right)\end{array}$ & 1.27 & 0.96 & 0.64 & 0.47 & 0.37 & 0.6 & 2.04 & 0.37 & 0.41 \\
\hline
\end{tabular}

Note:

$01-06$ - the sequence number of the specimens made of aluminum alloy $\mathrm{AlCuMg} 2$;

$10-12$ - the sequence number of the specimens made of copper SF-Cu

Table 2. Change in the roughness of the steel Fe360B processed specimens depending on the processing conditions

\begin{tabular}{|l|c|c|c|c|c|c|c|c|c|c|}
\hline Specimen, № & $\begin{array}{c}\mathbf{2 0} \\
\text { (ini) }\end{array}$ & $\begin{array}{c}\mathbf{2 1} \\
\text { (DS) }\end{array}$ & $\begin{array}{c}\mathbf{2 2} \\
(\mathbf{D S})\end{array}$ & $\mathbf{2 3}$ & $\mathbf{2 4}$ & $\mathbf{2 5}$ & $\mathbf{2 6}$ & $\mathbf{2 7}$ & $\mathbf{2 8}$ & $\mathbf{2 9}$ \\
\hline $\begin{array}{l}\text { Static load } \\
\left(P_{s l}, \mathrm{H}\right)\end{array}$ & - & 40 & 70 & 40 & 70 & 110 & 40 & 70 & 40 & 70 \\
\hline $\begin{array}{l}\text { Angle of oscillation } \\
\text { direction }\left(\beta,{ }^{\circ}\right)\end{array}$ & - & 0 & 0 & 0 & 0 & 0 & 30 & 30 & 45 & 45 \\
\hline $\begin{array}{l}\text { Roughness } \\
\left(R_{a}, \mu \mathrm{m}\right)\end{array}$ & 2.12 & 1.06 & 0.42 & 0.52 & 0.39 & 0.44 & 0.63 & 0.53 & 0.55 & 0.46 \\
\hline
\end{tabular}

Note: 20 - 29 - the sequence number of the specimens made of steel Fe360B

According to the results presented in Table 1 it is established that the lowest roughness of aluminum alloy $\mathrm{AlCuMg} 2$ specimens is observed for specimen 05 at the following technological parameters: $P_{s l}=40 \mathrm{H}, \beta=30^{\circ}$ (Figures 6 and 7). After the ultrasonic surface hardening of specimen 11 with the processing parameters $P_{s l}=60 \mathrm{H}, \beta=0^{\circ}, V=56$ $\mathrm{m} / \mathrm{min}$, the surface roughness changed from $2.04 \mu \mathrm{m}$ to $0.37 \mu \mathrm{m}$ (Figures 8 and 9 ). The application of the ultrasonic surface hardening allowed decreasing the roughness by more than 5 times in comparison with initial. 

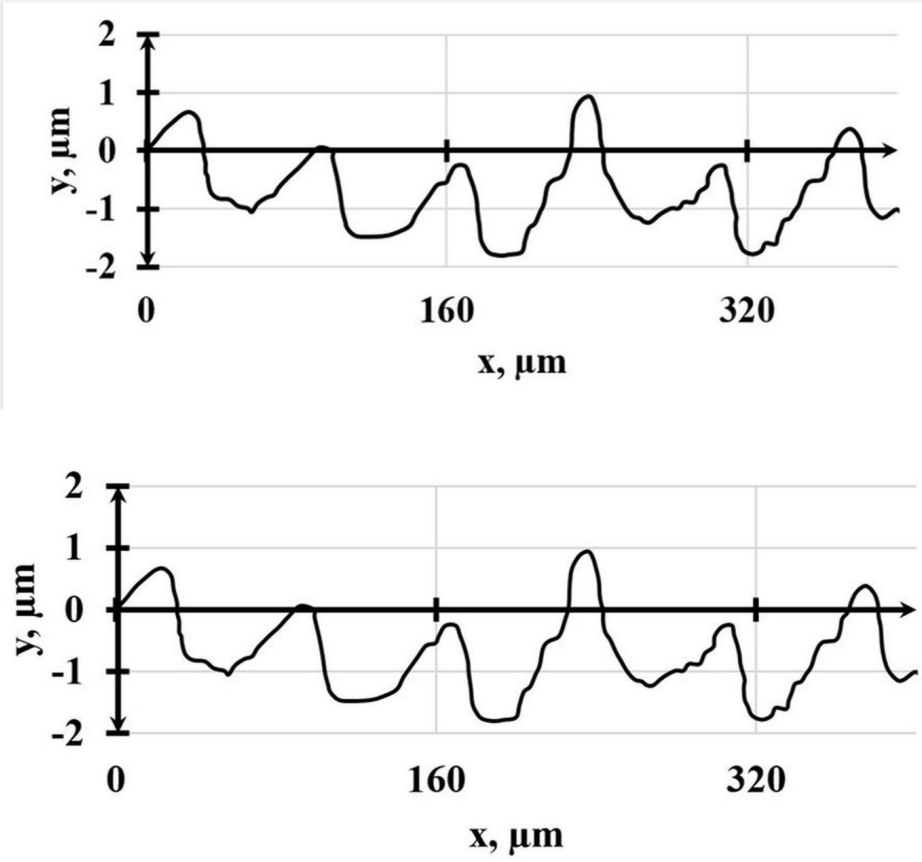

Fig. 6. Profile diagram of the initial surface of the specimen of aluminum alloy AlCuMg2 after the lathe processing

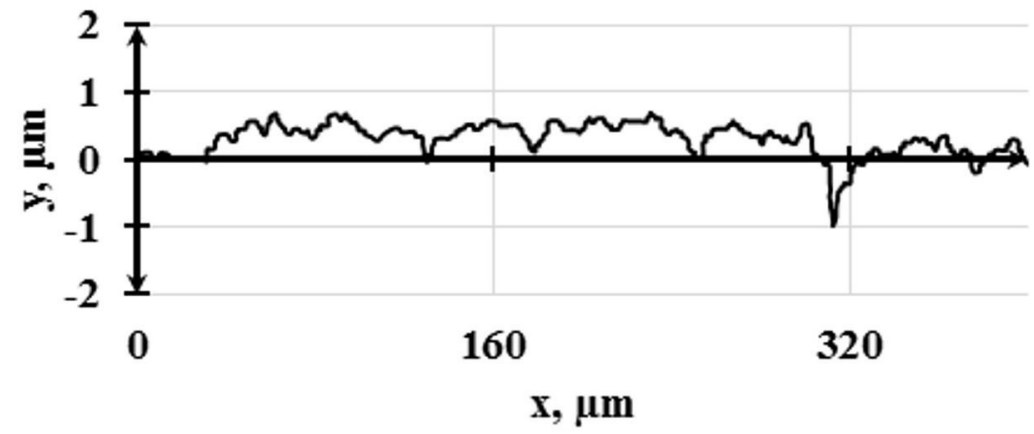

Fig. 7. Profile diagram of the surface of the specimen of aluminum alloy AlCuMg2 after the ultrasonic surface hardening $\left(P_{s l}=40 \mathrm{H}, V=56 \mathrm{~m} / \mathrm{min}, \beta=30^{\circ}\right)$

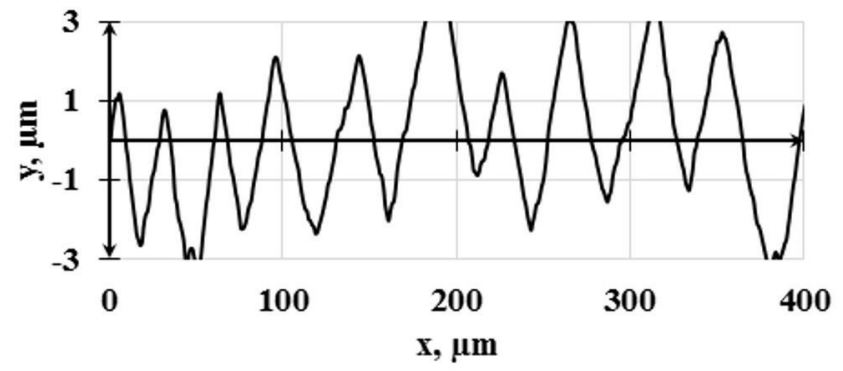


Fig. 8. Profile diagram of the initial surface of the specimen of copper SF-Cu after the lathe processing.

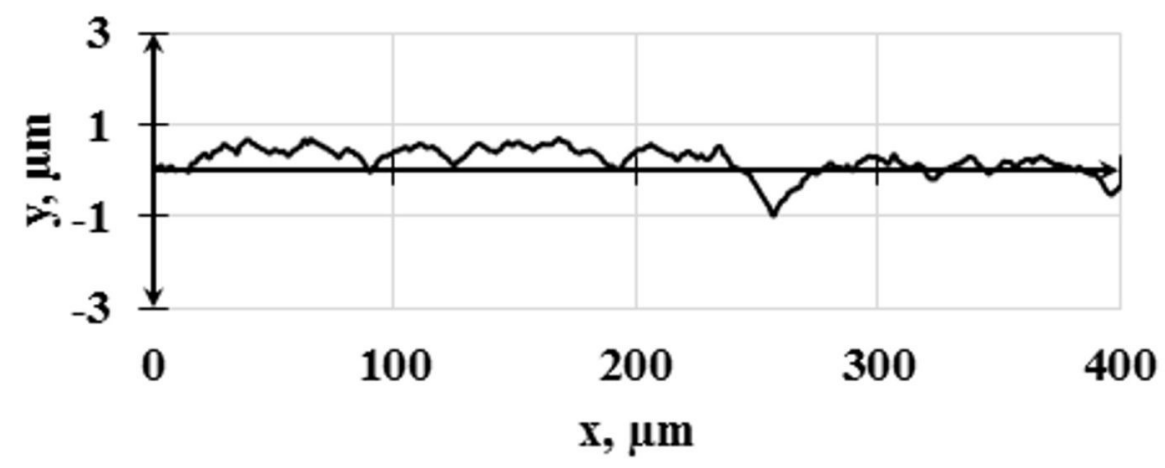

Fig. 9. Profile diagram of the surface of the specimen of copper SF-Cu after the after the ultrasonic surface hardening $\left(P_{s l}=60 \mathrm{H}, V=56 \mathrm{~m} / \mathrm{min}, \beta=0^{\circ}\right)$

A considerable decrease in the surface roughness (more than 5 times in comparison with initial) is also observed in the specimens made of steel Fe360B (Figures 10, 11). The best result was obtained at the following processing modes: $P_{s l}=70 \mathrm{H}, \beta=0^{\circ}$.

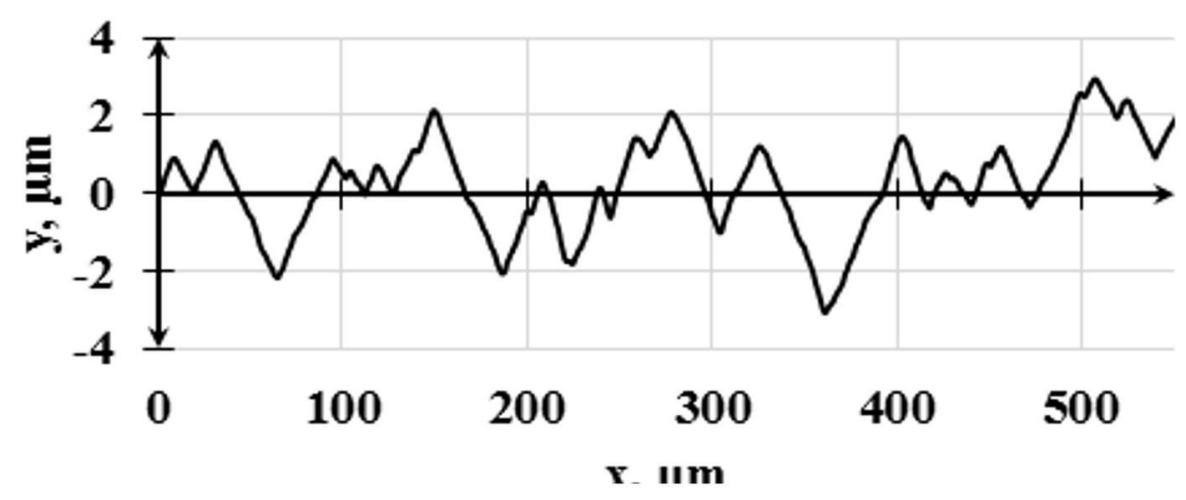

Fig. 10. Profile diagram of the initial surface of the specimen of steel Fe360B after the lathe processing. 


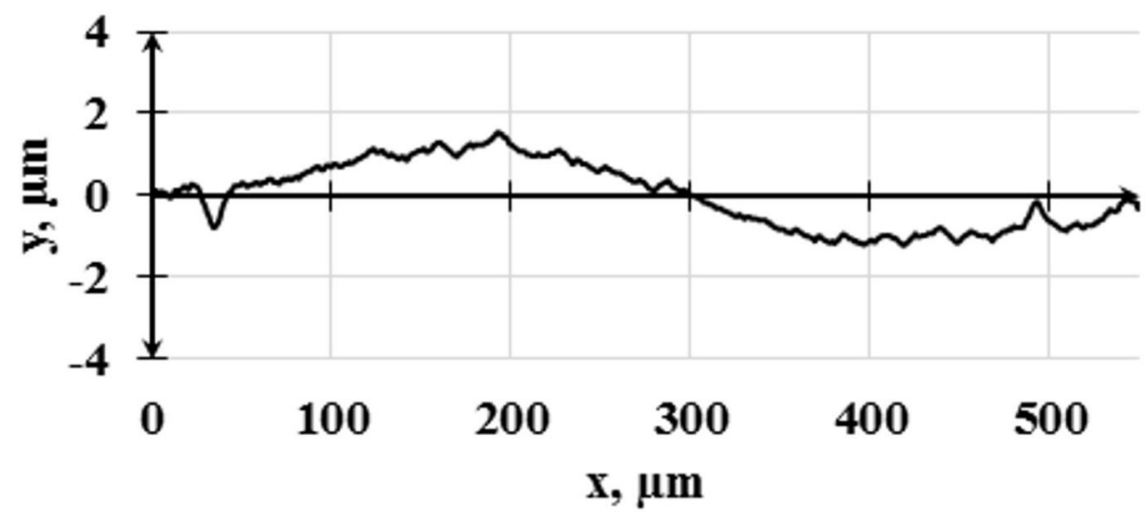

Fig. 11. Profile diagram of the surface of the specimen of steel Fe360B after the ultrasonic surface hardening $\left(P_{s l}=70 \mathrm{H}, V=37 \mathrm{~m} / \mathrm{min}, \beta=0^{\circ}\right)$

Profile diagrams presented show that in addition to the amplitude and spacing parameters there is a change in step characteristics and profile bearing length ratio and the surfaces become regular.

According the data obtained one can make a conclusion that the dependence of roughness on the load is of extreme character: in increasing the load to $70 \mathrm{H}$, there is a decrease in the surface roughness of specimens of steel Fe360B. The further growth in the static force leads to increasing the profile irregularity height.

As experiments show, the value of angle $\beta$ influences the micro-geometry parameters of the processed surface. The variation of angle $\beta$ from $0^{\circ}$ to $60^{\circ}$ causes the change in the altitude parameters of roughness.

The surface condition of the specimens before and after the processing is presented in Figures $12-14$.

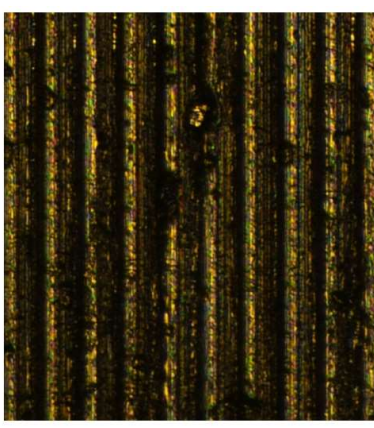

a

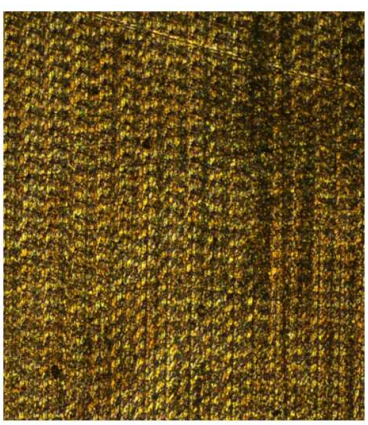

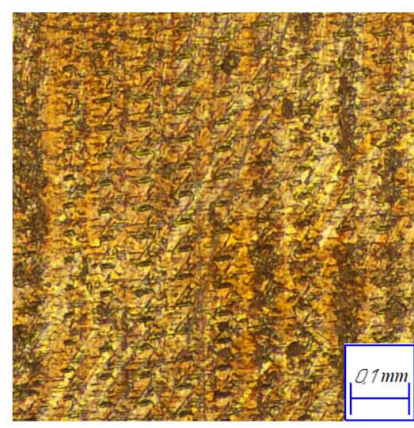

Fig. 12. Surface morphology of copper SF-Cu specimens: $\mathrm{a}$ - the initial surface; $\mathrm{b}$ - the ultrasonic surface hardening $\left(P_{s l}=60 \mathrm{H}, V=56 \mathrm{~m} / \mathrm{min}, \beta=0^{\circ}\right)$; - the ultrasonic surface hardening $\left(P_{s l}=60 \mathrm{H}\right.$, $\left.V=56 \mathrm{~m} / \mathrm{min}, \beta=60^{\circ}\right)$ 


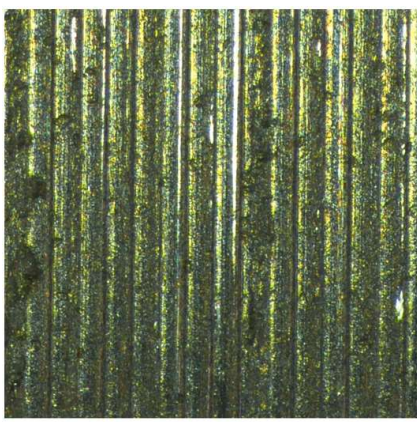

a

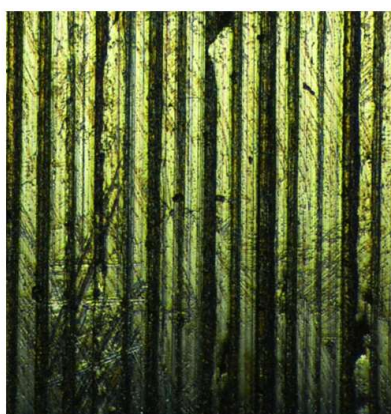

$\mathrm{b}$

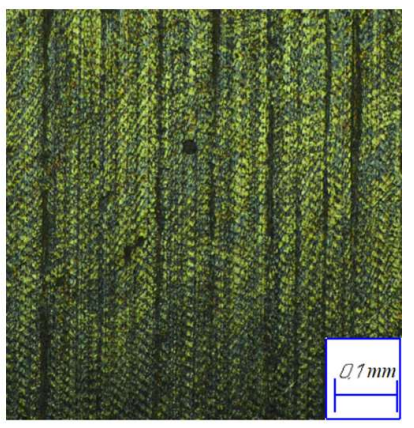

$\mathrm{C}$

Fig. 13. Surface state of steel Fe360B specimens: $\mathrm{a}$ - the initial surface; $\mathrm{b}$ - diamond smoothening $\left(P_{s l}\right.$ $=40 \mathrm{H}, \quad V=37 \mathrm{~m} / \mathrm{min}) ; \mathrm{c}-$ the ultrasonic surface hardening $\left(P_{s l}=40 \mathrm{H}\right.$, $V=37 \mathrm{~m} / \mathrm{min}, \beta=0^{\circ}$ )

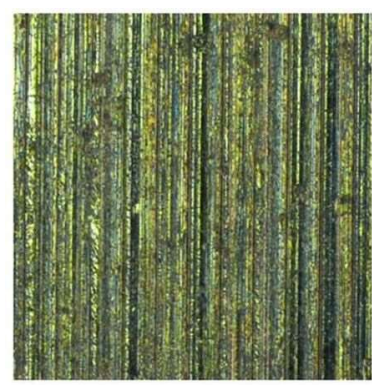

a

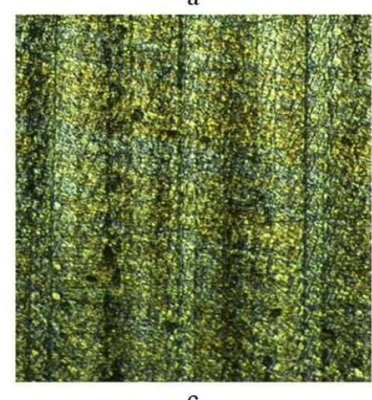

c
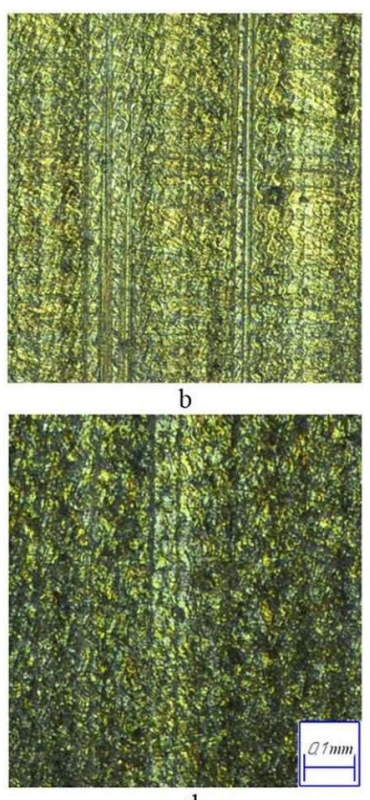

d

Fig. 14. Surface morphology of aluminum alloy AlCuMg2 specimens: $\mathrm{a}$ - the initial surface; $\mathrm{b}$ - the ultrasonic surface hardening $\left(P_{s l}=30 \mathrm{H}, V=89 \mathrm{~m} / \mathrm{min}, \beta=45^{\circ}\right)$; $\mathrm{c}$ the ultrasonic surface hardening $\left(P_{s l}=40 \mathrm{H}, V=89 \mathrm{~m} / \mathrm{min}, \beta=45^{\circ}\right) ; \mathrm{d}$ - the ultrasonic surface hardening $\left(P_{s l}=60 \mathrm{H}, V=89 \mathrm{~m} / \mathrm{min}, \beta\right.$ $\left.=45^{\circ}\right)$

It is seen from the figures presented that after the ultrasonic surface hardening with implementing the tangential oscillations to the processed surface of details made of steel $\mathrm{Fe} 360 \mathrm{~B}$, aluminum alloy $\mathrm{AlCuMg} 2$ and copper SF-Cu in the chosen range of technological parameters, there is a smoothing of roughness, and a well-ordered specific micro-geometry is formed without the surface waviness.

The comparison of surfaces after ultrasonic hardening (Figure 13, c) and the diamond smoothening (Figure 13, b) shows that they have a different structure. The ultrasonic surface hardening forms a regular cellular structure on the surface, which is not observed after the diamond smoothening. At the same velocity values, static load and supply, the ultrasonic surface hardening create s a new micro-relief on the entire surface with minor imprints of the previous processing, while after the diamond smoothening the number of imprints of 
the previous processing on the surface is considerable. It denotes that during the ultrasonic surface hardening there is a more intensive plastic deformation in the surface layer of details in comparison with the diamond smoothening.

\section{Conclusions}

According to the experiments made, the conclusions can be the following:

- the ultrasonic processing at the tangential oscillations of the indenter allows forming a stable micro-geometrical state of the surface layer with low values of the amplitude and spacing parameters on the details made of aluminum alloy $\mathrm{AlCuMg} 2$, copper SF-Cu and steel Fe360B;

- the application of the ultrasonic surface hardening with implementing the tangential oscillations to the processed surface allows forming a specific regular micro-geometry with a cellular structure;

- the angle of the oscillation $(\beta)$ is a technological factor of the ultrasonic surface hardening which allows changing the trajectory of the processing imprint and microgeometrical state of the surface;

- the ultrasonic surface hardening in comparison with the diamond smoothening provides a more intensive deforming of the surface layers of the processed details, which allows obtaining the required micrometer state at lower static loads;

- for specimens of aluminum alloy $\mathrm{AlCuMg} 2(105 \mathrm{HB})$ the lowest value of the arithmetical mean deviation of the profile $\left(R_{a}\right)$ is obtained at the following modes of the ultrasonic surface hardening: $P_{s l}=40 \mathrm{H}, \beta=30^{\circ}, S=0.07 \mathrm{~m} / \mathrm{min}, V=37 \mathrm{~m} / \mathrm{min}, 2 A=40$ $\mu \mathrm{m}$; and for samples of steel Fe360B (131 HB): $P_{s l}=70 \mathrm{H}, \beta=0^{\circ}, S=0.07 \mathrm{~m} / \mathrm{min}, V=37$ $\mathrm{m} / \mathrm{min}, 2 A=40 \mu \mathrm{m}$.

\section{References}

1. Qinglong Zhang, Zhanqi Hu, Wenwen Su, Haili Zhou, Changxin Liu, Yulin Yang, Xiaowen Qi.-, Surface and Coatings Technology, 321, 64 (2017)

2. T. Hisakado, Trans. Jap. Soc. Mech. Enges, 35, 53 (1975)

3. Tong-Yi, Zhang Wei-Hua Xu, Ming-Hao Zhao, Acta Materialia, 52, 57 (2004)

4. Efim Sh.Statnikov, Oleg V.Korolkov, Vladimir N.Vityazev, Supplement, Ultrasonics, 533 (2006)

5. Kh. M. Rakhimyanov, K. Kh. Rakhimyanov, A. Kh. Rakhimyanov, A. V. Kutyshkin, IOP Conference Series: Materials Science and Engineering, 126, 012015 (2016)

6. Kh.M.Rakhimyanov, Yu.V.Nikitin, Yu.S.Semenova, A.S.Eremina, IOP Conference Series: Materials Science and Engineering, 126, 012019 (2016)

7. Yang Bai, Ming Yang, Journal of Materials Processing Technology, 229, 367 (2016)

8. K. L. Johnson, Contact Mechanics (Cambridge University Press, 1985)

9. S. P. Chenakin, B. N.Mordyuk, N. I. Khripta, Applied Surface Science, 470, 44 (2019)

10. H. Xu, K. Komvopoulos, International Journal of Solids and Structures, 50, 876 (2013)

11. Hiroshi Ike, Journal of Materials Processing Technology, 138, 250 (2003)

12. I. A. Telkov, Procedia Engineering, 129, 981 (2015)

13. Liang Li, Miru Kim, Seungjun Lee, Munki Bae, Deugwoo Lee, Surface and Coatings Technology, 307, 517 (2016) 
14. Haiyang Zhou, Hongzhi Cui, Qing H. Qin, Journal of Materials Processing Tech, 251, 146 (2018)

15. S. Kumar, C. S. Wu, G. K. Padhy, W. Ding, Journal of Manufacturing Processes, 295 (2017) 